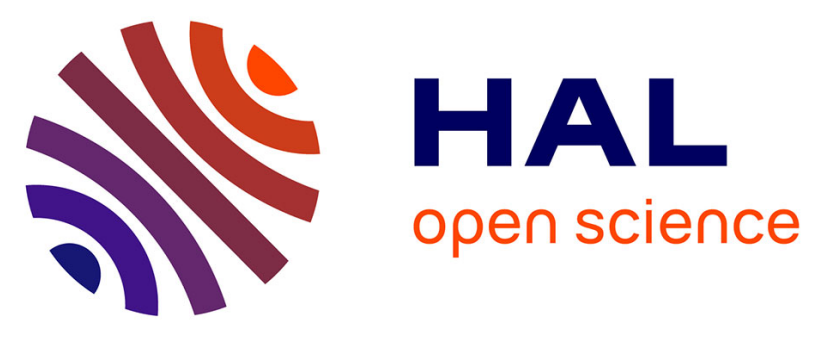

\title{
Liquids' atomization with two different nozzles: Modeling of the effects of some processing and formulation conditions by dimensional analysis
}

Sandra Mandato, Eric Rondet, Guillaume Delaplace, Amal Barkouti, Laurence Galet, Philippe Accart, Thierry Ruiz, Bernard Cuq

\section{To cite this version:}

Sandra Mandato, Eric Rondet, Guillaume Delaplace, Amal Barkouti, Laurence Galet, et al.. Liquids' atomization with two different nozzles: Modeling of the effects of some processing and formulation conditions by dimensional analysis. Powder Technology, 2012, 224, pp.323-330. 10.1016/j.powtec.2012.03.014 . hal-01267971

\section{HAL Id: hal-01267971 \\ https://hal.science/hal-01267971}

Submitted on 8 Nov 2019

HAL is a multi-disciplinary open access archive for the deposit and dissemination of scientific research documents, whether they are published or not. The documents may come from teaching and research institutions in France or abroad, or from public or private research centers.
L'archive ouverte pluridisciplinaire HAL, est destinée au dépôt et à la diffusion de documents scientifiques de niveau recherche, publiés ou non, émanant des établissements d'enseignement et de recherche français ou étrangers, des laboratoires publics ou privés. 


\title{
Liquids' atomization with two different nozzles: Modeling of the effects of some processing and formulation conditions by dimensional analysis
}

\author{
Sandra Mandato ${ }^{\mathrm{a}, *}$, Eric Rondet ${ }^{\mathrm{b}}$, Guillaume Delaplace ${ }^{\mathrm{c}}$, Amal Barkouti ${ }^{\mathrm{a}}$, Laurence Galet ${ }^{\mathrm{d}}$, \\ Philippe Accart ${ }^{\mathrm{d}}$, Thierry Ruiz ${ }^{\mathrm{a}}$, Bernard Cuq ${ }^{\mathrm{a}}$ \\ a U.M.R. 1208 IATE, Montpellier SupAgro, INRA, Université Montpellier 2, Bât. 37, 2 place Pierre Viala, 34060 Montpellier cedex 1, France \\ ${ }^{b}$ U.M.R. 95 QUALISUD, UFR des Sciences Pharmaceutiques et Biologiques, Laboratoire de Physique Moléculaire et Structurale, 15 avenue Charles Flahault, 34093 Montpellier cedex 5, France \\ ' INRA, U.R. 638 Processus aux Interfaces et Hygiène des Matériaux, F-59651, Villeneuve d'Ascq, France \\ d Centre RAPSODEE, FRE CNRS 3213, Université de Toulouse, Ecole des Mines d'Albi-Carmaux, 81013 Albi cedex 9, France
}

\begin{abstract}
A B S T R A C T
Liquid atomization is a largely widespread unit operation. The disintegration of a liquid into droplets depends on the nature of the nozzle, on the process parameters as well as physicochemical characteristics of the fluid. The aim of this work is to study the contribution of the process (liquid outlet speed and air pressure) and physicochemical (viscosity and surface tension) factors on the size distribution of droplets generated by single- and two-fluid flat spray nozzles. The obtained droplet median diameters which range between 77 and $594 \mu \mathrm{m}$ for the single-fluid nozzle and between 11 and $599 \mu \mathrm{m}$ for the two-fluid nozzle, are discussed in relation with operating conditions of atomization process. Dimensional analysis was performed as a modeling approach. Despite energy input for the droplet formation is known to be influenced by different origins according to single and two-fluid nozzles, it is shown that a unique correlation, with specific values of parameters for each nozzle type, gathers all the parameters affecting droplet size. In the range of process and formulation parameters tested, this correlation is validated and gives satisfactory agreement for the singleand two-fluid nozzles.
\end{abstract}

\section{Keywords:}

Drop

Process control

Multiphase flow

Atomization

Dimensional analysis

Agglomeration

\section{Introduction}

Liquid spraying is a unit operation largely widespread in many processes and industrial areas: automotive painting, waste incineration unit, pharmaceutical industry (spray-drying, spray congealing, and tablet coating), fuel atomization in combustion processes, mass transfer operations, food processing of granular products in fluid beds, coating of surfaces and particles, etc. [1-4]. In the specific case of wet granulation process in mixers or fluid beds, the control of the liquid droplet size distribution is a key step insofar a marked correlation has been found between the droplet size and that of the primary structures (i.e. nuclei) that are generated after the impact of the droplet on the powder bed [5]. This step of nuclei formation is of primary importance because it partly controls the extent of wet agglomeration mechanisms during which nuclei are associated in agglomerates [6,7]. Nucleation mechanisms have been described through two parameters [5]: (i) the kinetics of droplet penetration inside the powder bed that is largely controlled by formulation properties and (ii) the flux of droplets onto the bed surface which corresponds to the physical distribution of liquid in the spray zone and is described by the

\footnotetext{
* Corresponding author. Tel.: + 334996120 14; fax: + 33499613076 . E-mail address: mandato@supagro.inra.fr (S. Mandato).
}

dimensionless spray flux $\left(\psi_{\mathrm{a}}\right)$. The dimensionless spray flux is largely controlled by process parameters, but does not depend on the equipment [5]. The mastering of nucleation mechanisms is related to the values of the dimensionless spray flux, and thus to the fine characterization of sprayed droplet size. This is a challenge in many industries, and especially in couscous production from durum wheat semolina, where the nucleation and agglomeration stage directly controls the efficiency of the production line [8]. Moreover, the influence of the atomization process and formulation parameters on the spray angle is a critical key to manage the agglomeration process, as the spray angle partly determines the spray coverage on the powder bed.

Atomization refers to the disintegration of a liquid into droplets in a surrounding gas. The characteristics of the spray are highly dependent on the spray nozzle type. In single fluid nozzle, the liquid jet is formed thanks to the transformation of the pressure energy into kinetic energy when it crosses the nozzle. In two-fluid nozzles, the pressure of the compressed air is used to disperse the liquid in small droplets thanks to the shear forces which are exerted by the air of atomization on the liquid surface [9]. Two different types of two-fluid nozzles exist considering the position of the mixing nozzles which differs according to whether the compressed air comes into contact with the liquid to pulverize, either in the nozzle (i.e. internal mixing) or at the nozzle exit (i.e. external mixing) [3]. The phenomenon of atomization generates a high relative speed between the liquid 


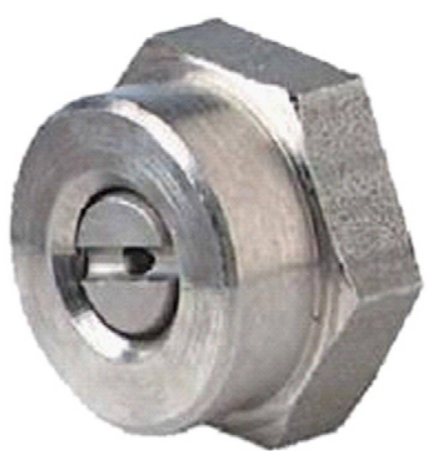

Fig. 1. Picture of the single-fluid atomization nozzle (Spraying Systems Co., France).

and the surrounding air. The higher is the relative speed, the higher are the frictional forces, the smaller is the resulting median diameter of the droplet [3]. The first phase of atomization involves the tearing of liquid into filaments and large droplets. The second phase is the breaking of these liquid forms into smaller and smaller droplets $[1,10]$. Droplet size depends on the nozzle type, process parameters, and physicochemical characteristics of the liquid.

The contribution of physicochemical properties of the liquid has been related to the effects of surface tension, viscosity, and density. It has been demonstrated that an increase in liquid density induces an increase in the droplet size [11]. As the viscosity and the surface tension vary jointly when formulating a liquid, it is still difficult to establish simple correlations between liquid properties and the droplet size. Generally, an increase in viscosity and/or surface tension of the liquid involves a rise in the droplet size [3,9,12-15]. For instance, Rajniak et al. [15] observed an increase in droplet size when increasing the concentration in hydroxypropyl cellulose of the liquid, that could be associated with both increases in viscosity and/or surface tension. It seems necessary to investigate separately the specific effects of the viscosity and the surface tension.

The process parameters (e.g. air pressure, liquid flow, spraying angle, temperature, etc.) also affect the sprayed droplet size. For instance when using a two-fluid nozzle, it has been shown that an increase in the liquid flow speed, a decrease in the air pressure, and a decrease in the spraying angle induce an increase in the droplet size $[3,16]$. The variation of the droplet Sauter mean diameter with the air density has been described by a decreasing power law [11]. In the specific case of two-fluid nozzles, the influence of the air pressure overrides that of the liquid flow. The relative pressure of the air (i.e. air flow in the nozzle) is the most effective atomization process parameter that affects the droplet size [2].

Many authors have developed empirical or semi-empirical models to predict the droplet size according to the spraying process and liquid physicochemical parameters [17-20]. These models are generally adapted for one nozzle geometry and narrow ranges of process and physicochemical parameters. We did not take note of a model making it possible to predict the size of droplets resulting from both singlefluid and two-fluid nozzles.

The aim of this work is to study the process and physicochemical parameters that control the size distribution of droplets generated by different nozzles. The studied process parameters are the nozzle type (single-fluid or two-fluid nozzles), the liquid outlet speed

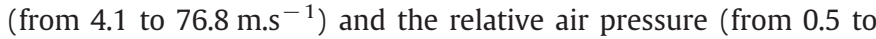
$2.5 \mathrm{bar}$ ). The selected physicochemical parameters are the fluid viscosity (from 1 to $259 \mathrm{mPa} . \mathrm{s}$ ) and surface tension (from 42 to $62.5 \mathrm{mN} / \mathrm{m}$ ). The results are compared and discussed in relation with operating conditions of atomization process. An original adimensional approach is led to mathematically describe the relationships between the droplet median diameter and the process and physicochemical parameters for both the single- and two-fluid nozzles.

\section{Materials and methods}

\subsection{Atomizing systems}

A single-fluid and an external two-fluid pneumatic atomizing systems (Spraying Systems Co., France) are used to produce a flat spray for the experiments. The single-fluid system (Fig. 1) can be equipped with two different nozzles (ref. 650017 and 6501), geometrically similar except for the inside diameters of the liquid outlet slit (respectively 0.28 and $0.66 \mathrm{~mm}$ ). The external two-fluid system is made of a combination of a liquid nozzle and a gas nozzle (Fig. 2). Three external two-fluid systems with three different ratios of the gas outlet area $\left(\mathrm{S}_{\mathrm{G}}\right.$, which corresponds to the inner area of the central gas outlet minus the outer area of the liquid outlet) to the inner liquid outlet area $\left(\mathrm{S}_{\mathrm{L}}\right)$ are used: 33.2 (ref. SUJE 416-50 combined with PAJ10550), 26.3 (ref. SUJE 418-50 with PAJ105-50), or 21 (ref. SUJE 420-50 with PAJ135-50) (Table 1). The higher is the inside diameter of the

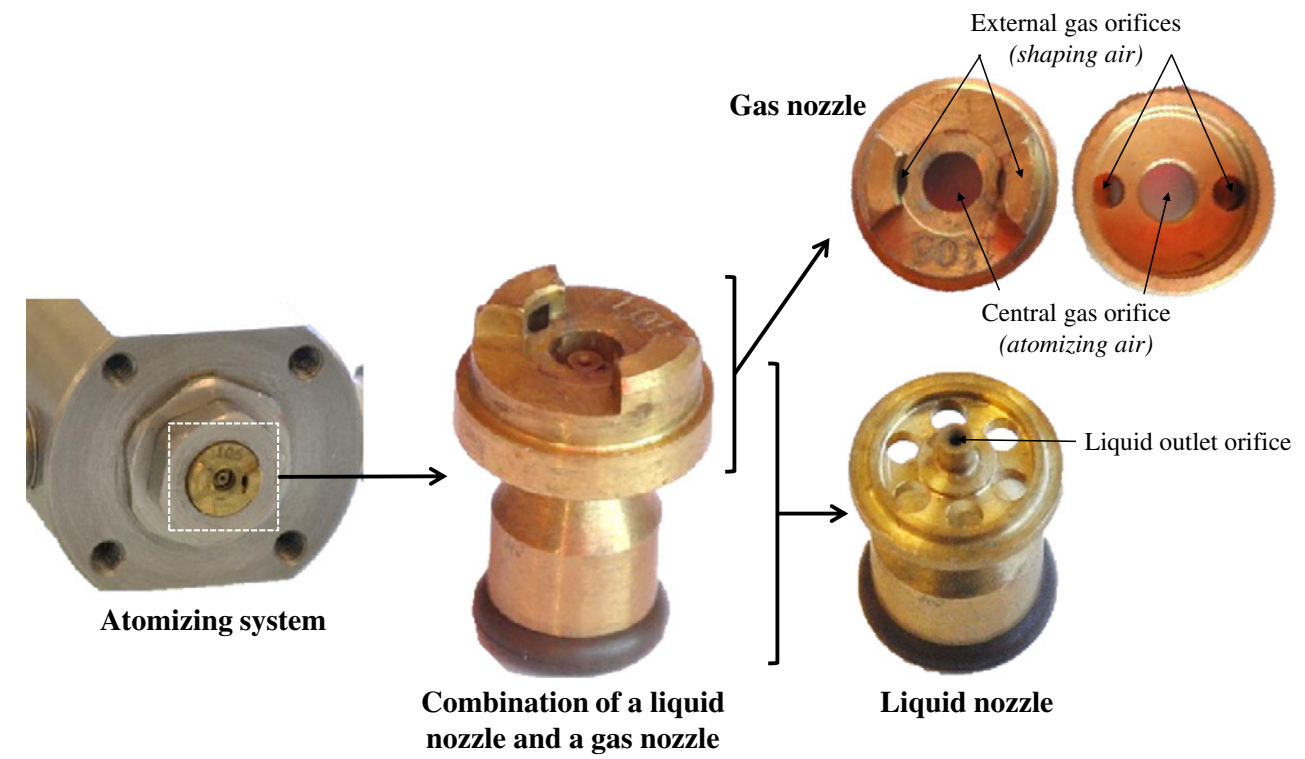

Fig. 2. Pictures of the external two-fluid atomization equipment (Spraying Systems Co., France). The gas outlet area $\left(\mathrm{S}_{\mathrm{G}}\right)$ corresponds to the inner area of the central gas outlet minus the outer area of the liquid outlet. 
Table 1

Principal dimensions of the three two-fluid atomizing systems used in the experiments.

\begin{tabular}{|c|c|c|c|c|}
\hline \multirow[b]{3}{*}{ Liquid nozzles } & \multirow[b]{3}{*}{$\begin{array}{l}\text { Inside diameters } \\
\text { of outlet slits } \\
(\mathrm{mm})\end{array}$} & \multicolumn{2}{|l|}{ Gas nozzles } & \multirow{3}{*}{$\begin{array}{l}\text { Gas-to-liquid ratios } \\
\text { of the outlet area } \\
\left(\mathrm{S}_{\mathrm{G}} / \mathrm{S}_{\mathrm{L}}\right)\end{array}$} \\
\hline & & PAJ $105-50$ & PAJ $135-50$ & \\
\hline & & 2.67 & 3.43 & \\
\hline SUJE 416-50 & 0.41 & $\mathrm{X}$ & & 33.2 \\
\hline SUJE 418-50 & 0.46 & $\mathrm{X}$ & & 26.3 \\
\hline SUJE $420-50$ & 0.51 & & $\mathrm{X}$ & 21 \\
\hline
\end{tabular}

liquid outlet slit, the higher are the liquid flow rates tested during atomization. Although it has been shown that the spray angle and the shape of the spray can be influenced by process parameters (water flow rate, air pressure) and liquid properties [3,9], we consider a constant flat spray angle of $50^{\circ}$ (supplier value) for the study.

Atomization experiments were carried out at $20^{\circ} \mathrm{C}$. The liquid is brought to the nozzle at constant flow rate using a peristaltic pump (520S/REM, Watson Marlow, France). Calibration of the liquid flow rate was carried out with water between 15.4 and $26.6 \mathrm{~m} . \mathrm{s}^{-1}$ for the single-fluid nozzles, and between 4.1 and $76.8 \mathrm{~m} . \mathrm{s}^{-1}$ under 0.5 bar of relative air pressure for the two-fluid nozzles. It was checked that the liquid flow rate measured at the outlet of the twofluid nozzles does not change significantly when relative air pressure is increased up to 2.5 bar. The relative air pressure for the two-fluid nozzles is adjusted (between 0.5 and 2.5 bar) using a pressure reducer. The influence of the outlet liquid speed was investigated between 15.4 and $26.6 \mathrm{~m} . \mathrm{s}^{-1}$ for the single-fluid nozzles and between 4.1 and $76.8 \mathrm{~m} . \mathrm{s}^{-1}$ for the two-fluid nozzles.

\subsection{Pulverized liquids}

To study the influence of viscosity and surface tension, experiments were carried out on different ternary mixtures based on deionized water, ethanol, and/or glycerin (Table 2). Ethanol was used to generate different surface tensions because its adsorption kinetic at

Table 2

Composition and physico-chemical properties of the selected atomized liquids (values of density are given \pm 0.02 ; values of viscosity are given $\pm 5 \%$ ).

\begin{tabular}{|c|c|c|c|c|c|c|}
\hline \multirow{2}{*}{$\begin{array}{l}\text { Nozzle } \\
\text { type }\end{array}$} & \multicolumn{3}{|c|}{ Liquid composition (w/w) } & \multirow{2}{*}{$\begin{array}{l}\text { Density } \\
\left(\mathrm{kg} / \mathrm{m}^{3}\right)\end{array}$} & \multirow{2}{*}{$\begin{array}{l}\text { Surface tension } \\
(\mathrm{mN} / \mathrm{m})\end{array}$} & \multirow{2}{*}{$\begin{array}{l}\text { Viscosity } \\
\text { (mPa.s) }\end{array}$} \\
\hline & Water & Ethanol & Glycerin & & & \\
\hline \multirow{12}{*}{$\begin{array}{l}\text { Single-fluid } \\
\text { nozzles }\end{array}$} & 100 & 0 & 0 & 1000 & $72( \pm 1.1)$ & 1 \\
\hline & 96.5 & 3.5 & 0 & 998 & $62.5( \pm 0.1)$ & 1 \\
\hline & 91.3 & 9.7 & 0 & 984 & $49( \pm 0.1)$ & 1 \\
\hline & 81.8 & 18.2 & 0 & 973 & $41( \pm 0.1)$ & 1 \\
\hline & 35.6 & 4.4 & 60 & 1146 & $49( \pm 0.1)$ & 10.6 \\
\hline & 25 & 0 & 75 & 1197 & $65.3( \pm 0.1)$ & 25.5 \\
\hline & 23.3 & 4.4 & 72.3 & 1179 & $49( \pm 0.2)$ & 25.5 \\
\hline & 20.3 & 10 & 69.7 & 1158 & $39.7( \pm 0.2)$ & 25.5 \\
\hline & 15.9 & 4.4 & 79.7 & - & $48.3( \pm 0.2)$ & 51.9 \\
\hline & 15.2 & 0 & 84.8 & 1223 & $63.4( \pm 0.1)$ & 72 \\
\hline & 12.8 & 4.4 & 82.8 & 1205 & $48.4( \pm 0.3)$ & 72.7 \\
\hline & 10 & 10 & 80 & 1182 & $42.5( \pm 0.4)$ & 71.8 \\
\hline \multirow{12}{*}{$\begin{array}{c}\text { Two-fluid } \\
\text { nozzles }\end{array}$} & 100 & 0 & 0 & 1000 & $72( \pm 1.1)$ & 1 \\
\hline & 96.5 & 3.5 & 0 & 998 & $62.5( \pm 0.1)$ & 1 \\
\hline & 91.3 & 9.7 & 0 & 984 & $49( \pm 0.1)$ & 1 \\
\hline & 81.8 & 18.2 & 0 & 973 & $41( \pm 0.1)$ & 1 \\
\hline & 15.6 & 4.4 & 80 & 1198 & $48.6( \pm 0.2)$ & 54.1 \\
\hline & 10.5 & 0 & 89.5 & 1235 & $62.8( \pm 0.1)$ & 134 \\
\hline & 4.4 & 7.9 & 87.7 & 1218 & $49.6( \pm 0.2)$ & 132 \\
\hline & 4.5 & 10 & 85.5 & 1194 & $40.8( \pm 0.4)$ & 132 \\
\hline & 4.8 & 4.4 & 90.8 & 1226 & $49.4( \pm 0.3)$ & 206 \\
\hline & 5.9 & 0 & 94.1 & 1247 & $64.3( \pm 0.2)$ & 259 \\
\hline & 3.1 & 4.4 & 92.4 & 1229 & $50.1( \pm 0.2)$ & 259 \\
\hline & 0 & 10 & 90 & 1205 & $41.6( \pm 1)$ & 259 \\
\hline
\end{tabular}

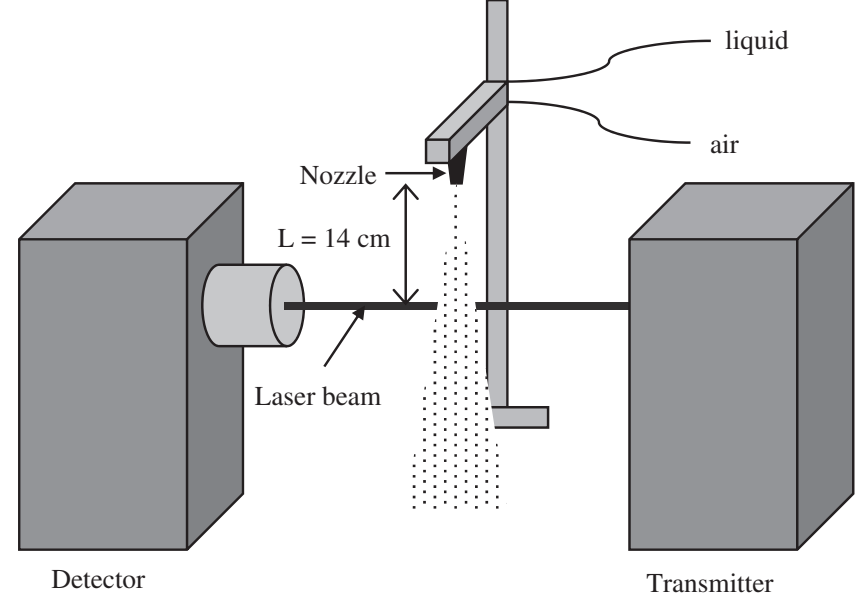

Fig. 3. Sketch of the atomization experiment.

the surface of droplets is instantaneous [10]. Glycerin was selected for its Newtonian behavior and for its aptitude to offer a large range of viscosity in the presence of water and ethanol. The surface tensions of the solutions (between 42 and $62.5 \mathrm{mN} / \mathrm{m}$ ) were measured in triplicate using a tensiometer Kruss K100 (Kruss, Germany) according to the method of the Wilhelmy plate. The viscosities of the solutions were measured using a rheometer Physica MCR 301 (Anton Paar, Austria) equipped with a double gap mobile. The densities of the solutions were measured using a $50 \mathrm{ml}$ liquid pycnometer. Preliminary tests were conducted to identify the maximal liquid viscosity ( 80 mPa.s) above which the liquid cannot be atomized using the single-fluid nozzles.

\subsection{Droplet size distribution measurement}

Liquid droplet sizes were measured by laser diffraction using the Spraytec $®$ (Malvern, France). The extremity of the nozzle is set at a fixed distance $\mathrm{L}=14 \mathrm{~cm}$ above the laser beam (Fig. 3 ) as it corresponds to the distance between the nozzle and the powder surface during the wet agglomeration process [7]. Droplet sizes were measured during $2 \mathrm{~min}$ and different parameters were calculated. The $\mathrm{d}_{10}, \mathrm{~d}_{50}$, and $\mathrm{d}_{90}$ volume diameters represent the equivalent diameters at which respectively 10,50 and $90 \%$ of the total volume of droplets are inferior. The Sauter mean diameter $\left(\mathrm{d}_{32}\right)$ is the diameter of a droplet having the same volume-to-surface area ratio as the total volume of all the droplets to the total surface area of all the droplets. The De Brouckere mean diameter corresponds to the mean of the volume distribution $\left(\mathrm{d}_{43}\right)$. The droplet size span is calculated as $\left(\mathrm{d}_{90}-\mathrm{d}_{10}\right) / \mathrm{d}_{50}$.

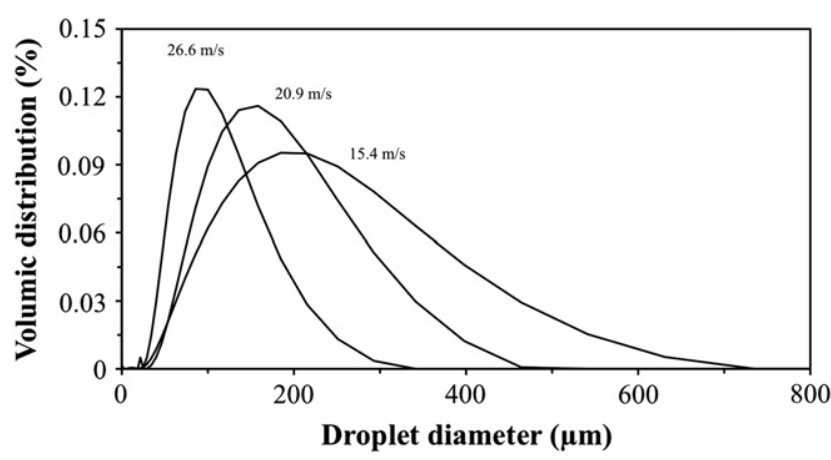

Fig. 4. Droplet size distributions after atomization of pure water using single-fluid nozzles of $0.66 \mathrm{~mm}$ inside diameter at outlet liquid speed of $26.6 \mathrm{~m} / \mathrm{s}$ and $20.9 \mathrm{~m} / \mathrm{s}$, and $0.28 \mathrm{~mm}$ inside diameter at outlet liquid speed of $15.4 \mathrm{~m} / \mathrm{s}$. 


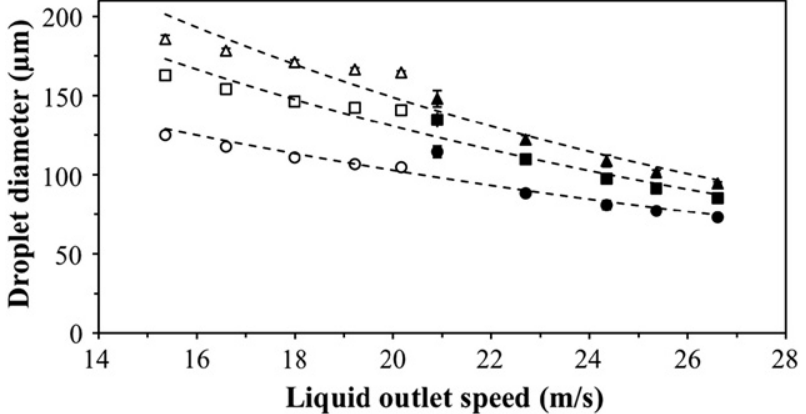

Fig. 5. Influence of liquid outlet speed on droplet diameters ( $d_{32}(O \mathbf{0}), d_{50}(\square \square)$, and $\mathrm{d}_{43}(\Delta \mathbf{\Lambda})$ ) after atomization of pure water using two different single-fluid nozzles, at $0.28 \mathrm{~mm}$ (white symbols) or at $0.66 \mathrm{~mm}$ (blacks symbols) inside diameters.

\section{Results and discussions}

\subsection{Liquid atomization with the single-fluid nozzles}

For the single-fluid nozzles, the droplets display monomodal size distributions, whatever the liquid outlet speed (Fig. 4). The measured droplet size distributions were described using different parameters $\left(\mathrm{d}_{10}, \mathrm{~d}_{50}, \mathrm{~d}_{90}, \mathrm{~d}_{32}\right.$, and $\left.\mathrm{d}_{43}\right)$. As illustrated in Fig. 5, we noticed that the effect of the liquid outlet speed on the droplet diameters $\left(d_{32}\right.$, $\mathrm{d}_{50}$, or $\mathrm{d}_{43}$ ) was almost similar whatever the considered size parameter. As in any case the size distribution was monomodal, we have thus chosen to discuss the influence of physicochemical and process parameters by only displaying the impact on the median diameter $\left(d_{50}\right)$ of the sprayed droplets.

\subsubsection{Influence of process parameters}

When using the single-fluid nozzles, any increase in the liquid outlet speed (from 15.4 to $26.6 \mathrm{~m} . \mathrm{s}^{-1}$ ) induces a large decrease in the droplet diameters ( $d_{50}$ varies from 163 to $85 \mu \mathrm{m}$ ) (Fig. 5). In pressure atomization of a liquid using a single-fluid nozzle, pressure is converted to kinetic energy to accelerate the liquid to a high speed, relative to the surrounding ambient air $[9,21]$. The increase of the liquid outlet speed leads to an increase in both the level of turbulence in the liquid jet and the aerodynamic drag forces exerted by the surrounding air, that both promote the disintegration of the liquid jet in smaller droplets.

\subsubsection{Influence of formulation parameters}

Under constant outlet liquid flow rate $\left(26.6 \mathrm{~m} . \mathrm{s}^{-1}\right)$ and using a low viscosity liquid (1 mPa.s), increases in the fluid surface tension do not affect the droplet diameter (Fig. 6). On the other hand, when using a more viscous liquid ( 25 or $72 \mathrm{mPa} . \mathrm{s}$ ), increases in the surface tension

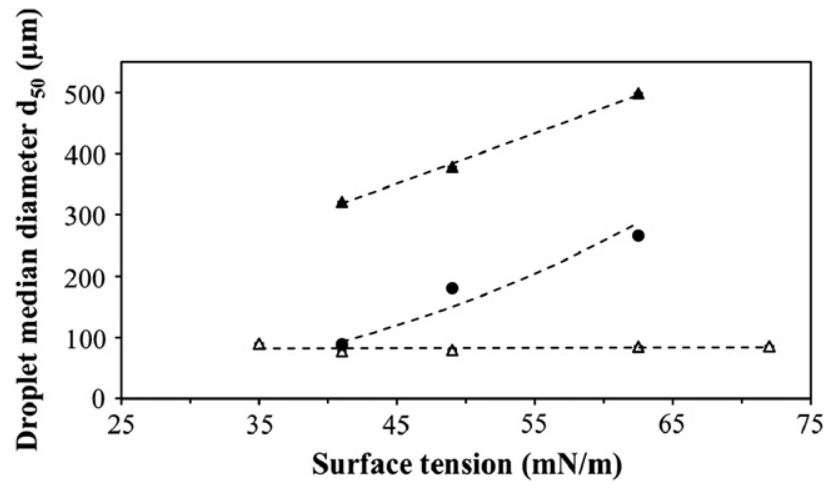

Fig. 6. Influence of liquid surface tension on droplet diameter $\left(d_{50}\right)$ after atomization of liquids of different viscosities (1 mPa.s $(\Delta), 25 \mathrm{mPa} . \mathrm{s}(\bullet)$, and $72 \mathrm{mPa} . \mathrm{s}(\boldsymbol{\Delta}))$ using a single-fluid nozzle $\left(0.66 \mathrm{~mm}\right.$ inside diameter) at liquid outlet speed of $26.6 \mathrm{~m} . \mathrm{s}^{-1}$.

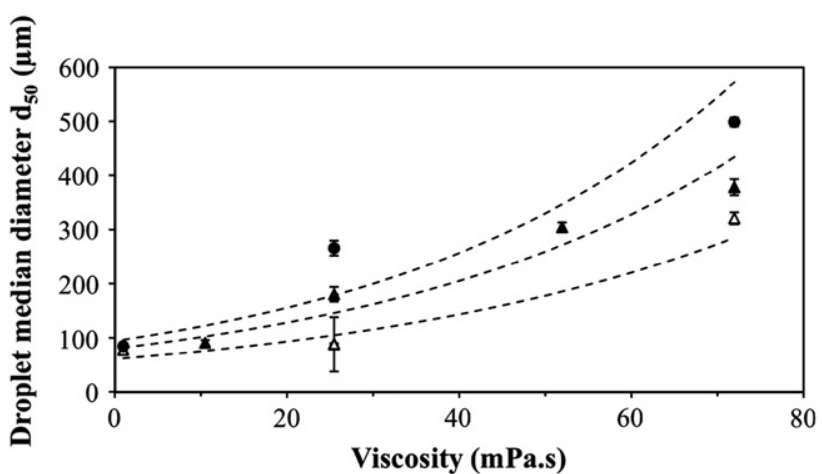

Fig. 7. Influence of liquid viscosity on droplet diameter $\left(d_{50}\right)$ after atomization of liquids of different surface tensions $\left(42 \mathrm{mN} \cdot \mathrm{m}^{-1}(\Delta), 49 \mathrm{mN} \cdot \mathrm{m}^{-1}(\mathbf{\Delta})\right.$, and $\left.62.5 \mathrm{mN} \cdot \mathrm{m}^{-1}(\bullet)\right)$ using a single-fluid nozzle $(0.66 \mathrm{~mm}$ inside diameter $)$ at liquid outlet speed of $26.6 \mathrm{~m} . \mathrm{s}^{-1}$.

induce an almost linear increase of the droplet diameter. For instance for a liquid at $25 \mathrm{mPa} . \mathrm{s}$ viscosity, the droplet diameter is tripled when the liquid surface tension increases from 41 to $62.5 \mathrm{mN} \cdot \mathrm{m}^{-1}$.

Whatever the liquid surface tension, we observe increases in the droplet diameter with liquid viscosity (Fig. 7). For instance for a liquid at $62.5 \mathrm{mN} \cdot \mathrm{m}^{-1}$ surface tension, the droplet diameter is multiplied by 5 when the liquid viscosity increases from 1 to $72 \mathrm{mPa}$.s. We thus observed that the ability of the liquid to resist the dynamic forces of atomization is increased with increasing viscosity and/or surface tension. In the case of single-fluid nozzles, an increase in liquid viscosity and/or surface tension has been found to hinder the liquid disintegration and lead to an increase in the amount of energy required for the atomization and also an increase in the droplet diameter [21-24].

\subsection{Liquid atomization with the two-fluid nozzles}

\subsubsection{Influence of process parameters}

When using the two-fluid nozzles, measurements of droplet size highlight monomodal droplet diameter distributions (Fig. 8). Increasing the air pressure from 0.5 to $2.5 \mathrm{bar}$, under constant liquid outlet speed $\left(4.1 \mathrm{~m} . \mathrm{s}^{-1}\right)$, induces the formation of smaller droplets and the tightening of the size distribution. When increasing the air pressure, the tightening of the droplet size distribution was observed, whatever the inside diameters of the outlet liquid slit. For instance, when using the two-fluid nozzle with $0.41 \mathrm{~mm}$ inside diameter, the diameter span decreases from 2.4 to 1.6 when the relative air pressure varies from 0.5 to 2.5 bar. These effects have been explained by the decrease in the number and volume of large droplets with higher air pressure $[16,25]$.

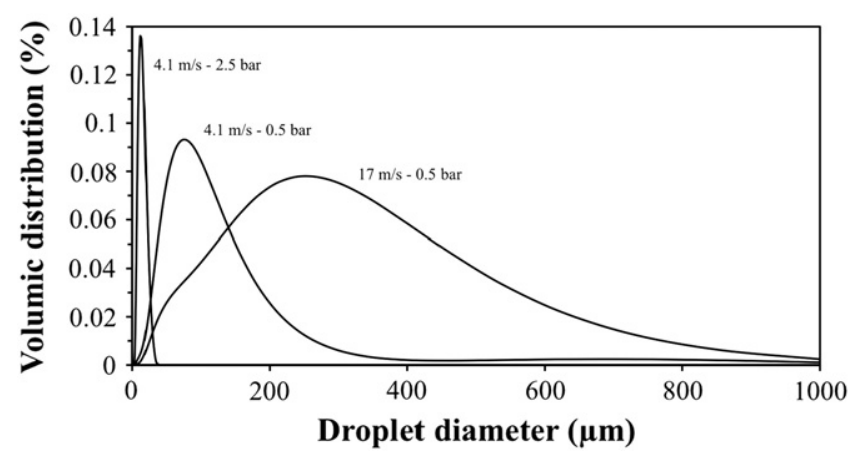

Fig. 8. Droplet size distributions after atomization of pure water using a two-fluid pneumatic nozzle $(0.41 \mathrm{~mm}$ inside diameter) for two different liquid flow rates and two different atomizing air pressures. 


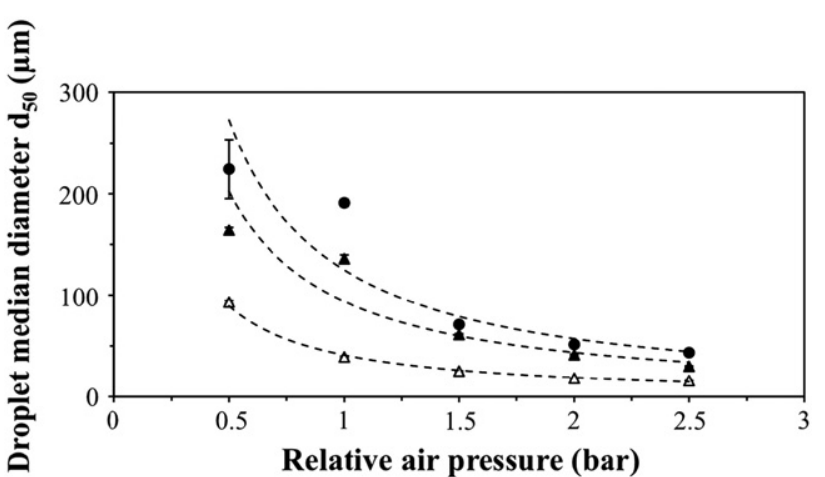

Fig. 9. Influence of relative air pressure on droplet diameter $\left(d_{50}\right)$ after atomization of pure water at $10 \mathrm{~m} \cdot \mathrm{s}^{-1}$ using three different two-fluid nozzles, at $0.41 \mathrm{~mm}(\Delta)$, at $0.46 \mathrm{~mm}(\boldsymbol{\Delta})$, or at $0.51 \mathrm{~mm}(\bullet)$ inside diameters.

An increase in relative air pressure (from 0.5 to 2.5 bar) also induces a decrease in the droplet diameters (Fig. 9). The relationships between droplet diameters and relative air pressure $(\mathrm{P})$ are described using power law models (Eq. (1)) whatever the liquid outlet speeds.

$d_{50} \propto P^{-1.11}$

Increasing the air pressure from 0.5 to 2.5 bar corresponds to an increase in the air outlet speed from 230 to $515 \mathrm{~m} . \mathrm{s}^{-1}$ which generates an increase in dynamic forces of atomizing air that causes the binder solution to atomize in smaller droplets $[3,11,16,23]$.

On the other hand an increase in liquid outlet speed (from 4.1 to $17 \mathrm{~m} . \mathrm{s}^{-1}$ ) under constant relative air pressure ( $\left.0.5 \mathrm{bar}\right)$ induces the formation of larger droplets and the broadening of the droplet size distribution (Fig. 8). This effect was observed whatever the inside diameters of the outlet liquid slit $(0.41,0.46$, or $0.51 \mathrm{~mm})$ (Fig. 10). For example, the diameter span is tripled when the liquid outlet speed varies from 4.1 to $46 \mathrm{~m} . \mathrm{s}^{-1}$, at 1.5 bar relative air pressure. Juslin et al. [16] also showed in the case of a pneumatic nozzle, that an increase of the liquid flow rate increases the width of diameter distributions, due to an increase of the amount of large droplets. The dependence of the $d_{50}$ with the liquid outlet speed can be correctly described $\left(R^{2}=0.947\right)$ using a simple exponential equation (Eq. (2)) whatever the three tested two-fluid nozzles (Fig. 10):

$d_{50}=\exp \left(0.034 v_{\text {liq }}\right)$

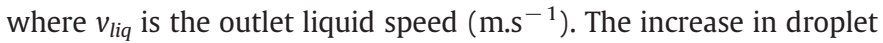
diameters with increasing liquid outlet speed has already been described in the case of two-fluid nozzles $[3,23,24]$.

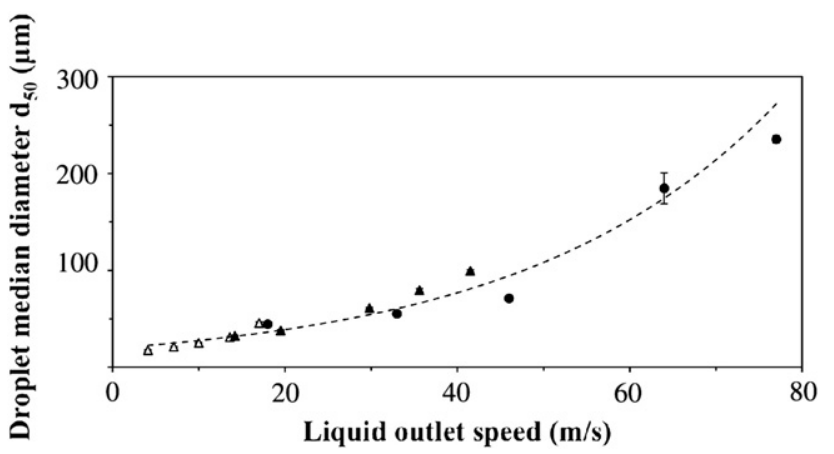

Fig. 10. Influence of liquid outlet speed on droplet diameter $\left(d_{50}\right)$ after atomization of pure water using three different two-fluid nozzles, at $0.41 \mathrm{~mm}(\Delta)$, at $0.46 \mathrm{~mm}(\mathbf{\Lambda})$, or at $0.51 \mathrm{~mm}(\bullet)$ inside diameters, for an atomizing relative air pressure of 1.5 bar.

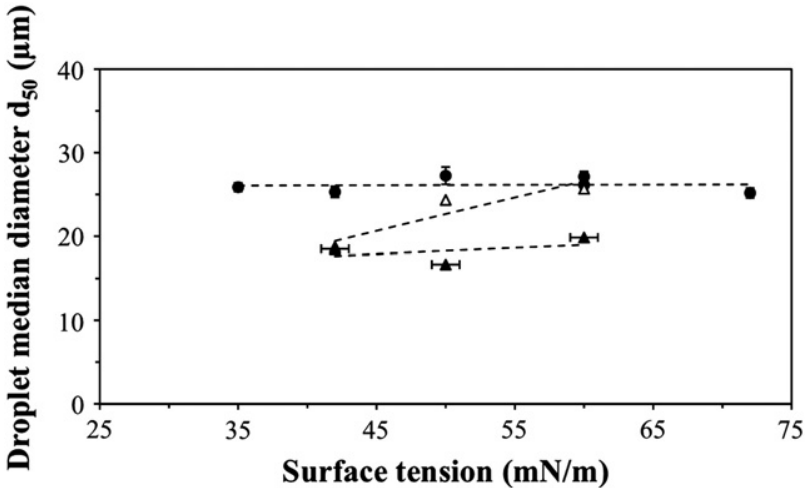

Fig. 11. Influence of liquid surface tension on droplet diameter $\left(d_{50}\right)$ after atomization of liquids of different viscosities ( $1 \mathrm{mPa} . \mathrm{s}(\Delta), 127 \mathrm{mPa} . \mathrm{s}(\boldsymbol{\Delta})$, and $259 \mathrm{mPa} . \mathrm{s}(\bullet))$ using a two-fluid nozzle $\left(0.41 \mathrm{~mm}\right.$ inside diameter) at $10 \mathrm{~m} . \mathrm{s}^{-1}$ and a relative air pressure of 1.5 bar.

\subsubsection{Influence of formulation parameters}

Using the two-fluid nozzles, the pulverization of liquid with different physicochemical parameters (viscosity and surface tension) does not seem to affect significantly the droplet size (Figs. 11 and 12). The selected process parameters (liquid outlet speed of $10 \mathrm{~m} \cdot \mathrm{s}^{-1}$ and relative air pressure of $1.5 \mathrm{bar}$ ) seem to overcome the specific influences of the fluid physicochemical parameters and control the fragmentation process.

For the two fluid nozzles, it is still very difficult to establish common rules concerning the influence of viscosity and surface tension on the droplet size. Several authors reported a marked influence of the viscosity on the droplet size. Juslin et al. [16] showed an increase of the droplet mean diameter (from 28.6 to $37.5 \mu \mathrm{m}$ ) with an increase in liquid viscosity (from 1 to $15 \mathrm{mPa}$.s) using a pneumatic two-fluid nozzle at 1.5 bar relative air pressure and 150 g.min ${ }^{-1}$ liquid flow rate. The ability of a liquid to resist the dynamic force of atomizing air has been supposed to increase with increasing the viscosity, which leads to larger droplet sizes. Rizkalla and Lefebvre [11] and Lefebvre [13] showed an increase in $\mathrm{d}_{32}$ with an increase in viscosity for an external mixing prefilming airblast atomizer. Hede et al. [3] also supposed that the effect on $\mathrm{d}_{32}$ upon an increase in the viscosity or the surface tension is due to an increase in the amount of energy required to atomize the spray. Other studies showed that the increase in viscosity does not affect the drop size $[1,14,26]$. Santangelo and Sojka [27] showed that the droplet diameter slightly decreased if the liquid surface tension increased.

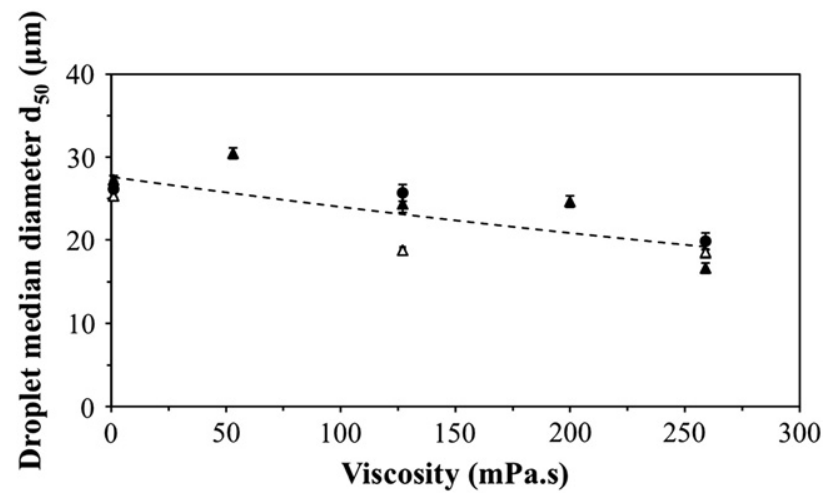

Fig. 12. Influence of liquid viscosity on droplet diameter $\left(d_{50}\right)$ after atomization of liquids of different surface tensions ( $42 \mathrm{mN} \cdot \mathrm{m}^{-1}(\Delta), 49 \mathrm{mN} . \mathrm{m}^{-1}(\boldsymbol{\Delta})$, and $62.5 \mathrm{mN} . \mathrm{m}^{-1}$ $(\bullet))$ using a two-fluid nozzle $(0.41 \mathrm{~mm}$ inside diameter $)$ at $10 \mathrm{~m} . \mathrm{s}^{-1}$ and a relative air pressure of 1.5 bar. 
Table 3

Definition of the starting variables and fundamental quantities used for the dimensional analysis of the liquid atomization.

\begin{tabular}{lllll}
\hline Dimensional variables & Symbol & \multicolumn{3}{l}{ Fundamental quantities } \\
\cline { 3 - 5 } & & $\mathrm{M}$ & $\mathrm{L}$ & $\mathrm{T}$ \\
\hline $\begin{array}{l}\text { Length between nozzle tip and drop } \\
\quad \text { size measurement position }\end{array}$ & $\mathrm{L}$ & 0 & 1 & 0 \\
Acceleration of gravity & & & & \\
Gas viscosity & $\mathrm{g}$ & 0 & 1 & -2 \\
Liquid viscosity & $\mu_{\mathrm{G}}$ & 1 & -1 & -1 \\
Gas density & $\mu_{\mathrm{L}}$ & 1 & -1 & -1 \\
Liquid density & $\rho_{\mathrm{G}}$ & 1 & -3 & 0 \\
Liquid surface tension & $\rho_{\mathrm{L}}$ & 1 & -3 & 0 \\
Liquid outlet area & $\sigma_{\mathrm{L}}$ & 1 & 0 & -2 \\
Gas outlet area & $\mathrm{S}_{\mathrm{L}}$ & 0 & 2 & 0 \\
Gas pressure & $\mathrm{S}_{\mathrm{G}}$ & 0 & 2 & 0 \\
Liquid outlet speed & $\mathrm{P}_{\mathrm{G}}$ & 1 & -1 & -2 \\
\hline
\end{tabular}

\subsection{Comparison of single-fluid nozzles and two-fluid nozzles}

Even if the effect of the liquid outlet speed for two-fluid nozzles (Fig. 10) seems to be opposed to that previously observed for single-fluid nozzles (Fig. 5), the formation of droplets spray is based on the same general mechanism and can be explained by a large differential of velocities between the two phases (air and liquid) whatever the nozzle type.

In the case of two-fluid nozzles, the air speeds (230 to $515 \mathrm{~m} . \mathrm{s}^{-1}$ ) are higher than the liquid speeds. An increase in the liquid outlet speed thus induces a decrease in the differential between air and liquid speeds. The lower destabilization energy reported to the liquid volume thus generates droplets of larger size due to the aerodynamic forces (Fig. 10). The relative liquid/air speed is a relevant parameter because it generates superficial waves with short wavelength that cause the fragmentation of the liquid jet [28]. Liquid outlet speed and air pressure thus plays a central role in the fragmentation of the liquid jet. We noticed that under high air pressure conditions, we observe a lower effect of liquid outlet speed on droplet diameter than under low air pressure conditions.

In the case of single-fluid nozzles, these mechanisms remain true. The liquid is sprayed with a high speed in a static ambient air. Any increase in the liquid outlet speed induces an increase in the differential between air and liquid speeds, enhancing frictional conditions and the formation of smaller drops.

In order to explain the specific effect of the viscosity and surface tension on the droplet diameters, it could have been interesting to consider the nature and the geometry of the selected nozzles and achieve a better understanding of the jet rupture mechanisms and drop formation for each nozzle type. Even if a predictive model can be established for a nozzle type under given process and physicochemical conditions, the highlighted correlation could not be directly transposed to other nozzle types and other process conditions. The atomization mechanism, which is specific for each nozzle, makes it difficult to highlight clear tendencies which would express the dependence of the droplet diameters according to the liquid surface tension and viscosity.

\subsection{Modeling using dimensional analysis}

The originality of our approach lies in the fact that we focus on the droplet diameter resulting from two different types of atomization nozzles (single-fluid and two-fluid nozzles) and different geometries (i.e. inside diameters). The tests were carried out on Newtonian fluids to avoid the shearing effect generated by the nozzle. We explored the effect of large ranges of process parameters (i.e. liquid outlet speed and air pressure) and physicochemical properties of the liquid (i.e. viscosity and surface tension). The air-to-liquid mass flow rate ratios were investigated between 0.06 and 5.11 (range $=5$ ). This range was of the same order of magnitude as the ranges (1.8-15) considered in most of the works dealing with atomization $[3,11,17,19,20]$.

From the experimental study, we aimed in developing an empirical correlation gathering in a unique process relationship all the experimental droplet sizes obtained whatever the operating conditions used (atomization conditions, physicochemical fluid properties, and nozzle geometrical parameters) by using the dimensional analysis [18]. This approach makes it possible to reduce the number of variables describing a physical problem using a set of dimensionless ratios. The number of ratios originally used to describe the problem can be obtained from the Buckingham theorem [29]. The first step of dimensional analysis consists in establishing the list of relevant dimensional parameters. In the case of liquid spraying, the relevant dimensional parameters and their fundamental quantities are listed in Table 3. The Buckingham theorem states that any physically meaningful equation involving $\mathrm{n}$ variables expressible in terms of $\mathrm{k}$ independent fundamental quantities can be rearranged into an equivalent equation involving a set of $\mathrm{p}(=\mathrm{n}-\mathrm{k})$ dimensionless variables which are derived as products of powers of the original variables $[9,23,29,30]$. In our study, we have listed 11 variables $(n)$ that can be expressed in terms of 3 fundamental quantities (k). Following the procedure described in Langhaar [31], we can obtain the dimensional matrix (not shown) that permits to express the dimensionless median diameter according to ' $\mathrm{p}=8$ ' dimensionless variables (Eq. (3)).

$$
\frac{d_{50}}{L}=f\left(\begin{array}{l}
\pi_{1}=\frac{\rho_{L}}{L^{-1.5} g^{-0.5} \mu_{G}} ; \pi_{2}=\frac{\rho_{G}}{\rho_{L}} ; \pi_{3}=\frac{\mu_{L}}{\mu_{G}} ; \pi_{4}=\frac{\sigma}{L^{0.5} g^{0.5} \mu_{G}} ; \pi_{5}=\frac{S_{G}}{S_{L}} ; \pi_{6}=\frac{S_{L}}{L^{2}} ; \\
\pi_{7}=\frac{P_{G}}{L^{-0.5} g^{0.5} \mu_{G}} ; \pi_{8}=\frac{V_{L}}{L^{0.5} g^{0.5}}
\end{array}\right)
$$

For each of the two atomization systems (single-fluid nozzles or two-fluid nozzles) the independent influences of the variation of each adimensional number on the value of $\mathrm{d}_{50} / \mathrm{L}$ were studied. This analysis made it possible to observe that $\mathrm{d}_{50} / \mathrm{L}$ values (for $\mathrm{L}=14 \mathrm{~cm}$ ) can be mathematically described by the following product of exponential and powers laws (Eq. (4)):

$$
\frac{d_{50}}{L}=K \pi_{1}^{\alpha_{1}} \pi_{2}^{\alpha_{2}} \pi_{4}^{\alpha_{4}} \pi_{5}^{\alpha_{5}} \pi_{6}^{\alpha_{6}} \pi_{7}^{\alpha_{7}} \exp \left(\beta_{3} \pi_{3}\right) \exp \left(\beta_{8} \pi_{8}\right)
$$

Table 4 summarizes the values taken by Eq. (4) parameters according to the two tested spraying system, single-fluid nozzles or two-fluid nozzles. Fig. 13 depicts the adjustment between the values of the dimensionless diameter described by the model $\left(\mathrm{d}_{50} / \mathrm{L}\right.$ predicted) and those experimentally obtained for the single-fluid nozzles and the two-fluid nozzles, whatever the process conditions and physicochemical fluid characteristics. We found that the proposed model (Eq. (4)) describes rather well the evolution of the droplet characteristic dimension whatever the nozzle type. Indeed, almost all experimental measurements are contained in a range corresponding to

\section{Table 4}

Parameters' value of Eq. (4) for the dimensional analysis of the liquid atomization, according to the spraying system.

\begin{tabular}{llcc}
\hline $\begin{array}{l}\text { Model } \\
\text { coefficients }\end{array}$ & Variables & $\begin{array}{l}\text { Mono-fluid } \\
\text { nozzles }\end{array}$ & Two-fluid nozzles \\
\hline $\mathrm{K}$ & - & 0.023 & $1.66 \cdot 10^{22}$ \\
$\alpha_{1}$ & Liquid density $\left(\pi_{1}\right)$ & 0.12 & 0.028 \\
$\alpha_{2}$ & Gas density $\left(\pi_{2}\right)$ & 0 & 0.03 \\
$\beta_{3}$ & Liquid viscosity $\left(\pi_{3}\right)$ & $4.34 \cdot 10^{-4}$ & $-4 \cdot 10^{-5}$ \\
$\alpha_{4}$ & Liquid surface tension $\left(\pi_{4}\right)$ & 1.17 & 0.019 \\
$\alpha_{5}$ & Gas outlet area $\left(\pi_{5}\right)$ & 0 & 0.94 \\
$\alpha_{6}$ & Liquid outlet area $\left(\pi_{6}\right)$ & 0 & 0.27 \\
$\alpha_{7}$ & Gas pressure $\left(\pi_{7}\right)$ & 0 & -2.2 \\
$\beta_{8}$ & Liquid outlet speed $\left(\pi_{8}\right)$ & -0.045 & 0.04 \\
\hline
\end{tabular}




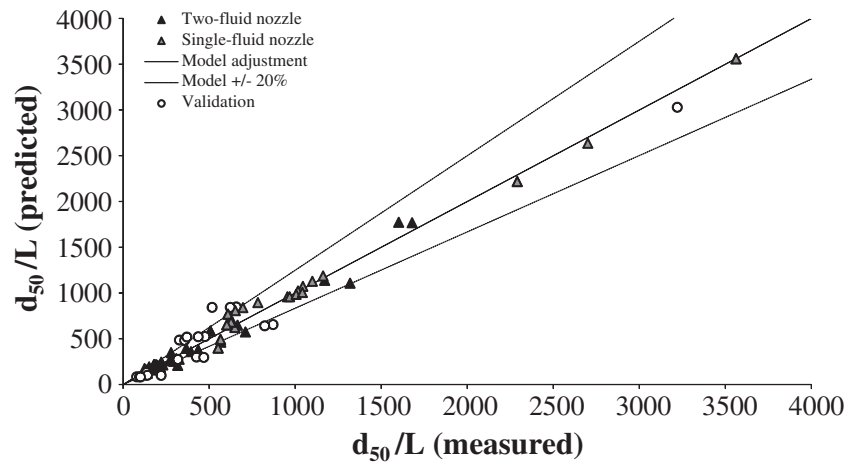

Fig. 13. Predicted versus experimental dimensionless droplet diameters for the single(gray triangles) and the two-fluid (black triangles) nozzles. The droplet size measurement was carried out with a laser beam placed at a fixed distance $\mathrm{L}=14 \mathrm{~cm}$ from the extremity of the nozzle. Validation points of the model are shown in white circles.

$\pm 20 \%$ of the value predicted by the model. The model was validated by tests carried out on the two spraying systems for process and physicochemical properties included in the investigated ranges (Fig. 13).

The values taken by Eq. (4) parameters (Table 4) make it possible to highlight the influence of process conditions. For the two-fluid nozzles, the liquid outlet speed has a direct positive influence on droplet size $\left(\beta_{8}=0.04\right)$. The air pressure $\left(\alpha_{7}=-2.2\right)$ is the most influencing parameter on the atomization, as the energy allowing the rupture of the liquid jet in drop is brought by the air pressure. The model also takes into account the geometrical aspects associated to the spraying system through the constants $\alpha_{5}$ and $\alpha_{6}$. Nozzle geometry is shown to have a significant incidence, especially when considering the ratio of the section of the gas outlet to that of the liquid outlet $\left(\alpha_{5}=0.94\right)$.

On the other hand for single-fluid nozzles, the liquid outlet speed has a negative influence on droplet size $\left(\beta_{8}=-0.045\right)$. The energy allowing the rupture of the jet in droplets only depends on the liquid pressure which is narrowly connected to its outlet speed (Fig. 5). The constants $\alpha_{5}$ and $\alpha_{6}$ are set to zero because there is no gas outlet, and because the effect of the variation of the nozzle liquid section is taken into consideration through the variation of the liquid outlet speed.

Concerning the influence of the physicochemical properties of the liquid, constants related to the density, surface tension, and viscosity $\left(\alpha_{1}, \beta_{3}\right.$ and $\left.\alpha_{4}\right)$ are very weak in the case of two-fluid nozzles, reinforcing the fact that process parameters are mainly controlling the droplet size. The influence of density $\left(\alpha_{1}\right)$ is relatively weak. An increase in liquid density generally produces a more compact spray that is less exposed to the atomizing action of the high-speed air and thus lead to a small increase in the droplet diameter $[11,13]$. On the other hand for single-fluid nozzles, physicochemical parameters highly affect the droplet size. The constant associated with the liquid surface tension $\left(\alpha_{4}=1.17\right)$ indicates an increase in the energy necessary to spray with an increase in surface tension. The low value of constant $\alpha_{1}$ indicates that the influence of density is relatively weak.

The suggested model thus makes it possible to consider the effects of the geometry of the atomizing systems (i.e. the liquid outlet slits which are different for the selected nozzles) through a unique equation (Eq. (4)).

\section{Conclusions}

When using two-fluid nozzles, the atomization mechanisms and the resulting droplet sizes are mainly affected by the air pressure. On the other hand, using single-fluid nozzles, the liquid physicochemical properties and the liquid outlet speed both display significant roles. Although the physical mechanisms subjacent with atomization in the two spraying systems are controlled by the differential speed between the air and the liquid, the different origins of the energy input explain the specific behavior (e.g. opposite influence of liquid speed) of the two nozzle types (single-fluid and two-fluid nozzles). According to this mechanism, it has been possible to develop an original and descriptive model based on an adimensional approach. A unique equation was proposed whatever the nozzle type and is associated with two sets of coefficients corresponding to the two types of nozzles. In order to improve the physical understanding of the underlying phenomenon, an experimental approach specially designed to allow the establishment of regime maps through the identification of well-known dimensionless numbers (e.g. Reynolds, Weber, etc.) could be further carried out.

\section{Acknowledgments}

The authors would like to thank the Agence Nationale de la Recherche (ANR ALIA 2008) for its financial support through the program "Reactive Powder".

\section{References}

[1] A. Aliseda, E.J. Hopfinger, J.C. Lasheras, D.M. Kremer, A. Berchielli, E.K. Connolly, Atomization of viscous and non-Newtonian liquids by a coaxial, high-speed gas jet. Experiments and droplet size modeling, International Journal of Multiphase Flow 34 (2008) 161-175.

[2] E. Babinsky, P.E. Sojka, Modeling drop size distributions, Progress in Energy and Combustion Science 28 (2002) 303-329.

[3] P.D. Hede, P. Bach, A.D. Jensen, Two-fluid spray atomisation and pneumatic nozzles for fluid bed coating/agglomeration purposes: a review, Chemical Engineering Science 63 (2008) 3821-3842.

[4] C. Larricq-Fourcade dit Lêride, Etude de la pulvérisation assistée en air d'une nappe liquide et influence d'un vent ionique sur les instabilités hydrodynamiques, PhD Thesis, Ecole Nationale Supérieure de l'Aéronautique et de l'Espace, France, 2006.

[5] S.M. Iveson, J.D. Litster, K. Hapgood, B.J. Ennis, Nucleation, growth and breakage phenomena in wet granulation processes, Powder Technology 117 (2001) 3-39.

[6] E. Rondet, M. Delalonde, T. Ruiz, J.P. Desfours, Fractal formation description of agglomeration in low shear mixer, Chemical Engineering Journal 164 (2010) 376-382.

[7] M.M. Saad, A. Barkouti, E. Rondet, T. Ruiz, B. Cuq, Study of agglomeration mechanisms of food powders: application to durum wheat semolina, Powder Technology 208 (2011) 399-408.

[8] J. Abecassis, G. Boggini, B. Cuq, H. Namoune, Other traditional durum derived products, in: M.J. Sissons, M. Carcea, M. Marchylo, J. Abecassis, Durum Wheat: Chemistry and Technology, second ed. AACC International, 2012, in press.

[9] T. Jimenez, Agglomération de particules par voie humide en lit fluidisé, PhD Thesis, Ecole Nationale Supérieure des Industries Agricoles et Alimentaires, France, 2007.

[10] P. Marmottant, Atomisation d'un liquide par un courant gazeux, PhD Thesis, Institut National Polytechnique de Grenoble, France, 2001.

[11] A.A. Rizkalla, A.H. Lefebvre, The influence of air and liquid properties on airblast atomisation, Journal of Fluids Engineering - Transactions of the ASME 97 (3) (1975) 316-320.

[12] C.E. Ejim, M.A. Rahman, A. Amirfazli, B.A. Fleck, Effects of liquid viscosity and surface tension on atomization in two-phase, gas/liquid fluid coker nozzles, Fuel 89 (2010) 1872-1882

[13] A.H. Lefebvre, Airblast atomization, Progress in Energy and Combustion Science 6 (1980) 233-261.

[14] M.T. Lund, P.E. Sojka, A.H. Lefebvre, P.G. Gosselin, Effervescent atomization at low mass flow rates. Part 1: the influence of surface tension, Atomization and Sprays 3 (1993) 77-89.

[15] P. Rajniak, C. Mancinelli, R.T. Chern, F. Stepanek, L. Farber, B.T. Hill, Experimental study of wet granulation in fluidized bed: impact of the binder properties on the granule morphology, International Journal of Pharmaceutics 334 (2007) 92-102.

[16] L. Juslin, O. Antikainen, P. Merkku, J. Yliruusi, Droplet size measurement: I. Effect of three independent variables on droplet size distribution and spray angle from a pneumatic nozzle, International Journal of Pharmaceutics 123 (1995) 247-256.

[17] J. Gretzinger, W.R. Marshall Jr., Characteristics of pneumatic atomisation, AIChE Journal 7 (1961) 312-318.

[18] K.Y. Kim, W.R. Marshall, Drop-size distributions from pneumatic atomisers, AIChE Journal 17 (1971) 575-584.

[19] B. Mulhem, U. Fritsching, G. Schulte, B. Bauckhage, Effect of solid particle characteristics on suspension atomization, Atomization and Sprays 133 (2003) 321-343.

[20] P. Walzel, Liquid atomisation, International Chemical Engineering 33 (1993) 46-60.

[21] H. Liu, Science and Engineering of Droplets - Fundamentals and Applications, William Andrew Publishing/Noyes, NY, 2000. 
[22] A.H. Lefebvre, Atomization and Sprays, Hemisphere Publishing Corporation, New York, 1989.

[23] R.J. Schick, Spray Technology Reference Guide: Understanding Drop Size, Spray Analysis and Research Services, Spray Drying Systems Co., USA, 2006.

[24] Spray Drying Systems Co., Engineers' guide to spray drying technology, Spray Drying Systems Co., USA, 2000.

[25] M.M. Elkotb, M.A. Mahdy, M.E. Montaser, Investigation of external-mixing airblast atomizers, Proc. 2nd Int. Conf. Liq. Atomization Spray, 1982, pp. 107-115.

[26] H.N. Buckner, P.E. Sojka, Effervescent atomization of high-viscosity fluids: part I, Newtonian liquids, Atomization and Sprays 1 (1991) 239-252.
[27] P.J. Santangelo, P.E. Sojka, A holographic investigation of the near nozzle structure of an effervescent atomizer produced spray, Atomization and Sprays 5 (1995) 137-155.

[28] M. De Luca, Contribution à la modélisation de la pulvérisation d'un liquide phytosanitaire en vue de réduire les pollutions, PhD Thesis, Université de la Méditerranée, Aix-Marseille II, France, 2007.

[29] G. Miragliotta, The power of dimensional analysis in production systems design, International Journal of Production Economics 131 (2011) 175-182.

[30] K. Masters, Spray Drying Handbook, John Wiley \& Sons, New York, 1976.

[31] H.L. Langhaar, Dimensional Analysis and Theory of Models, John Wiley \& Sons, New York, 1951. 